Thorax (1949), 4, 110.

\title{
POST-OPERATIVE RESPIRATORY COMPLICATIONS A STUDY OF 1,000 GENITO-URINARY CASES BY
}

\author{
K. J. MANN
}

From the E.M.S. Genito-Urinary Unit, Colindale Hospital, London, N.W.9

The occurrence of post-operative respiratory complications has occupied the attention of clinicians for the past few decades. Radiographs have established the incidence and frequency of these complications, but the aetiology and pathology of some of them have remained obscure. The present investigation therefore was undertaken in the hope of throwing some light on these problems. It was carried out in a genito-urinary unit and is related to 1,000 operations carried out on 810 patients, all of whom received the usual pre- medication, followed by gas, oxygen, and ether anaesthesia.

\section{INCIDENCE}

One hundred and sixty post-operative complica tions were encountered in 144 patients. Thus $16 \%$ of all operations carried out were followed byo respiratory complications in $18 \%$ of the patientse

The complications are classified according to their probable aetiology in Table I. Sixteen pee cent. were regarded as vascular in origin, $10 \%$

TABLE I

Classification of 160 Respiratory Complications Related to Age Groups

\begin{tabular}{|c|c|c|c|c|c|c|c|}
\hline \multirow{2}{*}{ Type of Complication } & \multicolumn{6}{|c|}{ Age Group } & \multirow{2}{*}{ No. } \\
\hline & $0-29$ & $30-39$ & $40-49$ & $50-59$ & $60-69$ & $70+$ & \\
\hline $\begin{array}{lll}\text { Group A: Vascular } & & \\
\text { Emboli } \because \text { oedema } & \ldots & . \\
\text { Pulmonary oedemates } & . & . \\
\text { Pleural transudates } & . & . \\
\text { Ileus of herniated gut } & . & .\end{array}$ & $\frac{1}{-}$ & $\frac{1}{-}$ & $\frac{2}{1}$ & $\begin{array}{l}3 \\
\frac{1}{1}\end{array}$ & $\begin{array}{l}8 \\
3 \\
1 \\
-\end{array}$ & $\frac{4}{-}$ & $\begin{array}{r}19 \\
4 \\
2 \\
2 \\
\text { Total } 26\end{array}$ \\
\hline 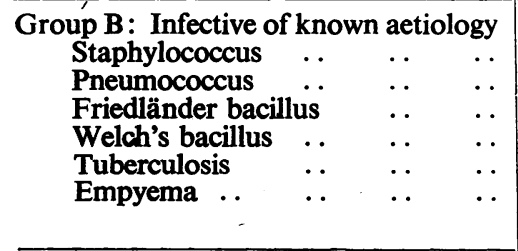 & $\begin{array}{l}1 \\
- \\
-\end{array}$ & $\begin{array}{l}\bar{z} \\
\bar{z} \\
\bar{z}\end{array}$ & $\begin{array}{l}1 \\
\text { E } \\
\text { - }\end{array}$ & $\frac{-}{\frac{1}{1}}$ & $\frac{\frac{1}{3}}{\frac{1}{1}}$ & $\frac{1}{\frac{1}{1}}$ & $\begin{array}{r}4 \\
7 \\
1 \\
2 \\
1 \\
1 \\
\text { Total } 16\end{array}$ \\
\hline 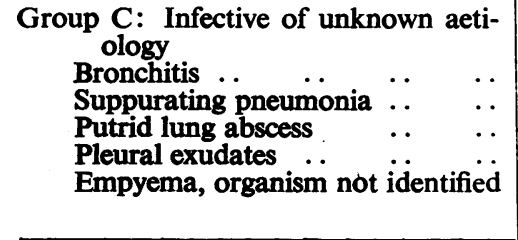 & $\frac{2}{z}$ & $\begin{array}{l}2 \\
= \\
-\end{array}$ & $\frac{3}{\frac{2}{-}}$ & $\begin{array}{l}3 \\
1 \\
1 \\
3 \\
2\end{array}$ & $\frac{23}{\frac{3}{3}}$ & $\begin{array}{l}7 \\
1 \\
1 \\
- \\
-\end{array}$ & $\begin{array}{rr}40 \\
2 \\
2 \\
8 \\
2 \\
\text { Total } 54\end{array}$ \\
\hline $\begin{array}{l}\text { Group D: } \\
\text { Pulmonary lesions of unknown } \\
\text { aetiology } \\
\end{array}$ & 1 & 2 & 5 & 24 & 25 & 7 & Total 64 \\
\hline Total in each age group: & 5 & 5 & 14 & 41 & 69 & 26 & \\
\hline
\end{tabular}


TABLE II

Summary of Incidence of Post-operative Complications Reported by Different AUthors

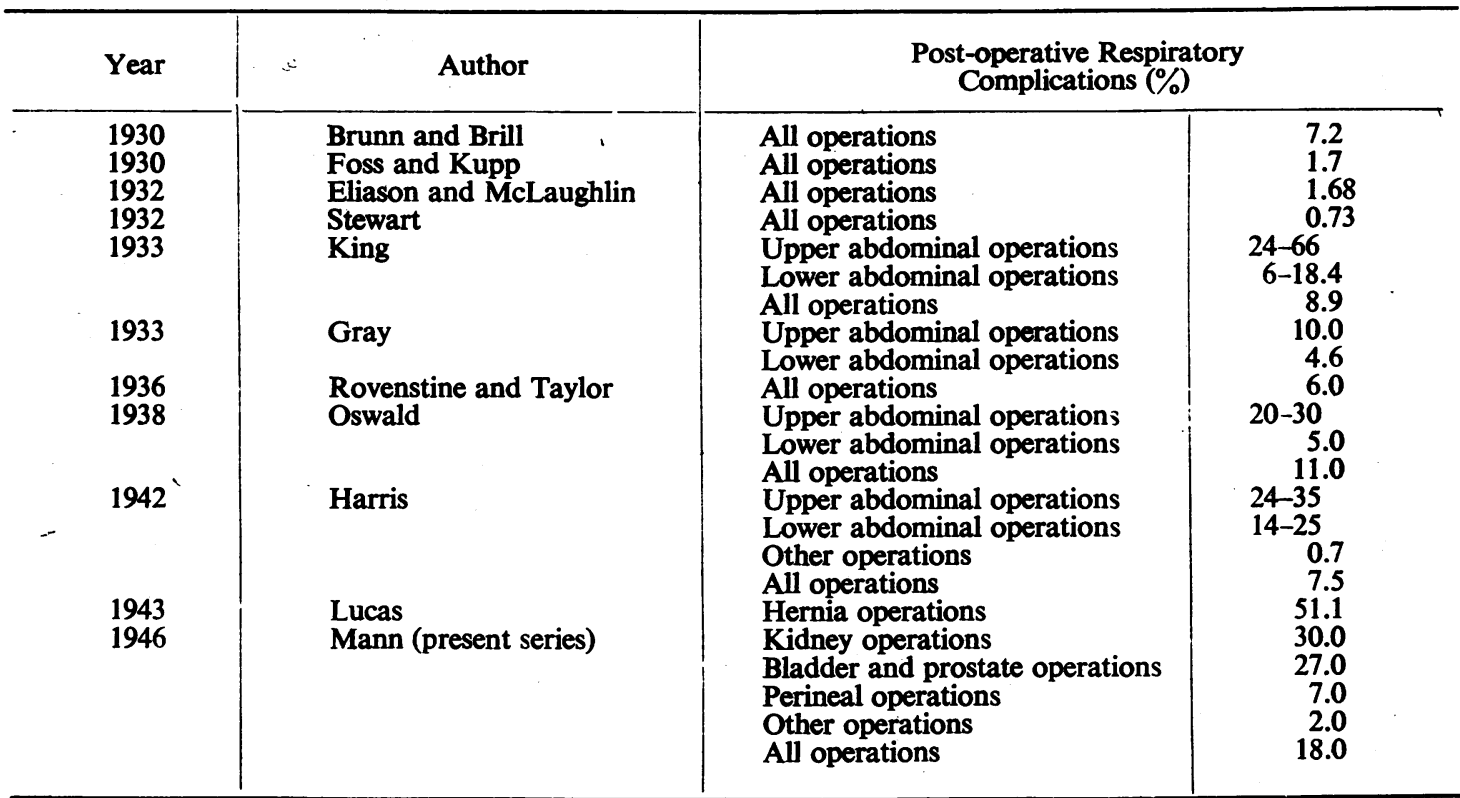

as infective complications of known aetiology, and $34 \%$ as infective complications of unknown aetiology. In the remaining $40 \%$ the pathological and aetiological basis remained in doubt.

The personal interest taken by different authors in the elucidation of respiratory complications, the nature of the material studied, and the inclusion of minor degrees of these complications by some and not by others may explain some of the discrepancies in Table II.

It can be 'seen from Table III that $19.5 \%$ of the men suffered from post-operative respiratory com- plications, but only $4.4 \%$ of the women. Boland and Sheret (1928) found the incidence in men and women to be $18 \%$ and $8 \%$ respectively. King's (1933) figures also show these complications to be twice as frequent in men as in women.

It is interesting that although in women the incidence of respiratory complications remains under $10 \%$ in all age groups, in men it rises steeply above 40 years of age. This predisposition of older patients to post-operative respiratory complications is reported by Oswald (1938), who noticed $100 \%$ increase.

TABLE III

InCidence of Respiratory Complications in Relation to Age and SeX

\begin{tabular}{c|c|c|c|c|c|c}
\hline & \multicolumn{3}{|c|}{ Men } & \multicolumn{3}{c}{ Women } \\
\cline { 2 - 7 } Age & No. of Patients & $\begin{array}{c}\text { Post-operative } \\
\text { Complications }\end{array}$ & Percentage & No. of Patients & $\begin{array}{c}\text { Post-operative } \\
\text { Complications }\end{array}$ & Percentage \\
\hline $0-9$ & 4 & 0 & 0 & 1 & 0 & 0 \\
$10-19$ & 14 & 0 & 0 & 4 & 0 & 0 \\
$20-29$ & 30 & 3 & 10.0 & 1 & 0 & 0 \\
$30-39$ & 32 & 3 & 9.4 & 20 & 10.0 \\
$40-49$ & 74 & 13 & 17.6 & 19 & 0 & 0.3 \\
$50-59$ & 154 & 32 & 20.8 & 19 & 0 & 0 \\
$60-69$ & 265 & 65 & 24.5 & 17 & 1 & 10.0 \\
$70+$ & 146 & 24 & 16.4 & 10 & 4 & 4.4 \\
\hline All ages & 719 & 140 & 19.5 & 91 & 4 & \\
\hline
\end{tabular}


TABLE IV

InCidence of Respiratory Complications With and Without Pre-operative Abnormality

\begin{tabular}{|c|c|c|c|c|c|c|c|}
\hline \multirow{2}{*}{\multicolumn{2}{|c|}{. }} & \multicolumn{3}{|c|}{$\begin{array}{c}\text { With Cardiovascular or Respiratory } \\
\text { Abnormality }\end{array}$} & \multicolumn{3}{|c|}{$\begin{array}{l}\text { Without Cardiovascular or Respiratory } \\
\text { Abnorinality }\end{array}$} \\
\hline & & $\begin{array}{l}\text { No. of } \\
\text { Patients }\end{array}$ & $\begin{array}{l}\text { No. of } \\
\text { Patients with } \\
\text { Post-operative } \\
\text { Complications }\end{array}$ & $\begin{array}{c}\text { Post-operative } \\
\text { Complications } \\
(\%)\end{array}$ & $\begin{array}{l}\text { No. of } \\
\text { Patients }\end{array}$ & $\begin{array}{l}\text { No. of } \\
\text { Patients with } \\
\text { Post-operative } \\
\text { Complications }\end{array}$ & $\begin{array}{c}\text { Post-operative } \\
\text { Complications } \\
(\%)\end{array}$ \\
\hline 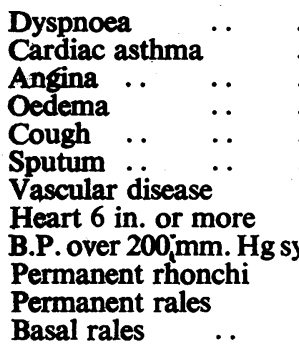 & $\begin{array}{l}\ldots \\
\ldots \\
\cdots \\
\cdots \\
\cdots \\
\cdots \\
\cdots \\
\ldots \\
\ldots \\
\ldots\end{array}$ & $\begin{array}{r}142 \\
12 \\
11 \\
-28 \\
225 \\
214 \\
268 \\
78 \\
105 \\
40 \\
2 \\
28\end{array}$ & $\begin{array}{r}28 \\
4 \\
3 \\
4 \\
55 \\
54 \\
42 \\
17 \\
19 \\
20 \\
2 \\
5\end{array}$ & $\begin{array}{r}20 \\
33 \\
27 \\
14 \\
25 \\
25 \\
15 \\
21 \\
18 \\
50 \\
100 \\
18\end{array}$ & $\begin{array}{l}668 \\
798 \\
799 \\
782 \\
585 \\
596 \\
542 \\
732 \\
705 \\
770 \\
142 \\
782\end{array}$ & $\begin{array}{r}116 \\
140 \\
141 \\
116 \\
89 \\
90 \\
102 \\
127 \\
125 \\
124 \\
808 \\
139\end{array}$ & $\begin{array}{l}17.5 \\
18 \\
19 \\
15 \\
15 \\
15 \\
18 \\
17 \\
17 \\
16 \\
17 \\
18\end{array}$ \\
\hline
\end{tabular}

The general health of the patients, determined by clinical impression, weight, blood count, estimation of blood protein, is an important factor in influencing the frequency of post-operative respiratory complications. Of the total number of patients, 473 were in good, and 337 in fair or poor, health. Of the former $13 \%$, and of the latter $25 \%$, developed respiratory complications, these variations being significant.

In order to estimate the effect of pre-operative cardiovascular and respiratory symptoms and signs on the incidence of post-operative respiratory complications, the patients were divided into two groups: those with and those without the abnormality in question (Table IV). Although patients with cardiac asthma and angina show a higher incidence of respiratory complications, pulmonary oedema was the complication in four out of the seven patients. Inflammatory or "idiopathic" pulmonary complications are not more

TABLE V

analysis of Radiological abnormalities in Relation to Post-operative Complications

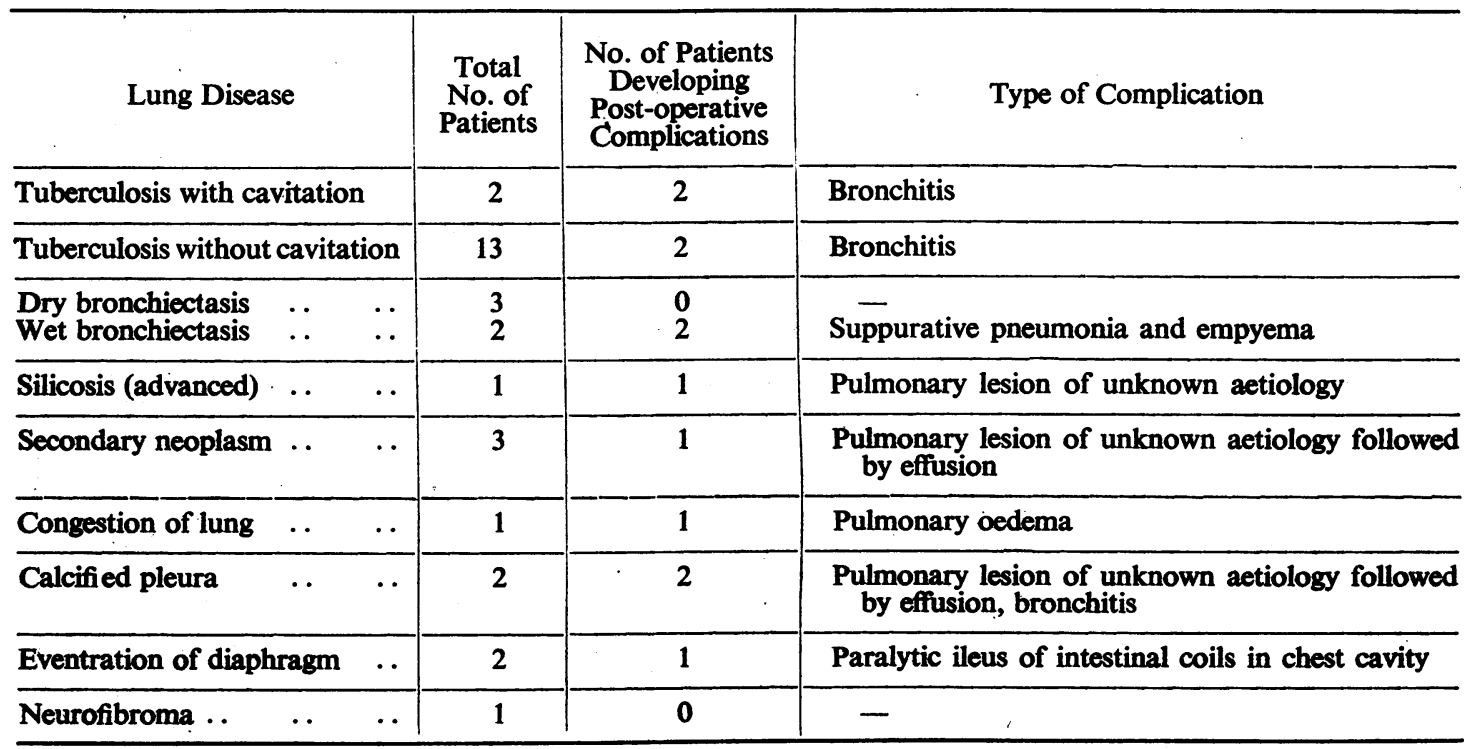


frequent in this group of patients than in others without these symptoms.

On the other hand, the history of cough and sputum and the finding of constant rhonchi and generalized rales seems to be related to the development of respiratory complications. These symptoms and signs reflect the state of health of the respiratory tract, disease of which predisposes to post-operative respiratory complications. This conclusion is supported by the analysis of 400 patients' pre-operative radiographs (Table V). Of these, $\mathbf{3 7 0}$ showed no pulmonary lesions of clinical significance ; 30 , however, showed definite radiological abnormalities. It appears that lung lesions not complicated by infection of the respiratory tract (e.g., non-cavitating tuberculosis, dry bronchiectasis) do not increase the incidence of respiratory complications. The latter are, however, encountered in a high proportion of cases with pre-operative septic pulmonary diseases (wet bronchiectasis), or in patients whose pulmonary efficiency is greatly reduced (complete pleural calcification).

The importance of abdominal operations in the incidence of respiratory complications has been stressed by many authors (Armstrong, 1906 ; Pasteur, 1914 ; Holmes, 1924 ; Churchill, 1925 ; Scrimger, 1922 ; Scott, 1925 ; Mastics and others, 1927 ; Boland and Sheret, 1928 ; King, 1933 ; Harris, 1942 ; and others). In the present investigation corresponding findings were noted (Table VI).

TABLE VI

Respiratory COMPLiCATIONS AFTER ABDOMINAL OPERATIONS

\begin{tabular}{|c|c|c|c|}
\hline Operation & $\begin{array}{c}\text { No. of } \\
\text { Patients with } \\
\text { Complications }\end{array}$ & $\begin{array}{c}\text { No. of } \\
\text { Operations }\end{array}$ & $\begin{array}{c}\text { Compli- } \\
\text { cations } \\
(\%)\end{array}$ \\
\hline $\begin{array}{l}\text { Kidney } \\
\text { Suprapubic } \quad \ldots \\
\text { Scrotal } \\
\text { Transurethral }\end{array}$ & $\begin{array}{r}31 \\
117 \\
7 \\
5\end{array}$ & $\begin{array}{r}106 \\
427 \\
.98 \\
369\end{array}$ & $\begin{array}{r}30 \\
27 \\
7 \\
2\end{array}$ \\
\hline
\end{tabular}

The incidence of respiratory complications following abdominal operations amounted to $30 \%$, compared with $7 \%$ following scrotal operation in which no abdominal muscles were cut, and with $2 \%$ following operation in which no external incision was made.

\section{Aetiology}

It appears that the most important factors which predispose the patient to post-operative respiratory complications are his age, sex, general condition, local condition of respiratory passages, and degree of trauma inflicted on the abdominal muscles. Knowledge of these factors does not, however, imply knowledge of the precipitating aetiological agent, nor of the pathological changes caused by it. The respiratory complications encountered in the present investigation were seen to fall into four groups (Table I). In three of these the pathological process underlying the clinical picture is definite and known, being vascular in the first and inflammatory in the second and third. In the fourth group, however, it remains obscure, mainly because of the recovery of the patients suffering from these complications and the consequent lack of post-mortem material for the elucidation of the pathological changes. The following discussion, therefore, will be concerned first with the pathological changes responsible for the production of the pulmonary lesions in this group, and secondly with factors precipitating these changes.

Three factors, embolism, atelectasis, and infection, singly or in combination, might account for the sudden appearance of lung changes in the post-operative period.

The embolic origin of this type of respiratory complication was put forward, especially by Cutler and Morton (1917) and Cutler and Hunt (1920). The evidence in its favour is, however, meagre. The time of onset, the symptoms, and the signs produced by pulmonary embolus are different from those encountered in the respiratory complications under discussion. In the absence of definite pathological evidence in its support the embolic theory of the origin of the lung changes in this fourth group of respiratory complications must be discarded.

The factor of infection used to be taken as the cause of these pulmonary lesions. In the course of the last few decades it has been superseded by the assumption that atelectasis is the main responsible factor. This swing of opinion has occurred as a result of experimental and clinical evidence accumulating since the beginning of the present century.

Experimental and Radiological Evidence.Experimentally, atelectasis has been produced by mechanical obstruction of the air passages, and occasionally by the interruption of nervous impulses to and from the lungs (Mendelssohn, 1845 ; Traube, 1846 ; Lichtheim, 1878 ; MacCallum, 1908; Andrus, 1925; Coryllos and Birnbaum, 1928; Lee, Ravdin, Tucker, and Pendergrass, 1923). The radiological appearances thus produced were found to be indistinguishable from those produced in post-operative lung lesions. 
Clinical evidence in support of the theory that atelectasis is the main factor in the pathogenesis of the lung changes in this group of complications was first produced by Pasteur (1914) and simultaneously by Elliot and Dingley (1914). The sudden onset of symptoms, the tenacious sputum unlike that of pneumococcal pneumonia, the basal localization of the disease, and the displacement of the mediastinum both clinically and radiologically were all quoted to support atelectasis as the cause of the lung changes.

Lately, with the increased use of the bronchoscope, further evidence was cited by different observers (Jackson and Lee, 1925; Hearn and Clerf, 1927 ; Mathes and Holman, 1929 ; Brunn and Brill, 1930 ; and others) in support of atelectasis. Tenacious sputum was found blocking the bronchi to the affected lung, and cures have been reported as a result of bronchial aspiration.

With the experimental production of atelectasis in the dog by mucus aspirated from the bronchi of a patient suffering from post-operative lung lesion (Lee, Ravdin, Tucker, and Pendergrass, 1923), the evidence was accepted as complete, with the result that practically every post-operative lung complication is now diagnosed as atelectasis and treatment is instituted accordingly. But a critical review of all the evidence quoted above will throw doubt on atelectasis as a primary factor in the pathogenesis of these lesions.

The experimental production of atelectasis is an established fact, and so is the rare occurrence of primary atelectasis in man either by interference with the neurological innervation of the respiratory apparatus or by obstruction of the bronchi. There is also no doubt that the radiological pictures produced by atelectasis in animals and spontaneously in man are similar in appearance to those obtained in the respiratory lesions under discussion. To argue from that that the two diseases are precipitated by the same factor is fallacious. It is known that similar radiological appearances may occur in a variety of lung lesions having nothing in common but that similarity. Coryllos and Birnbaum (1928) pointed out the absolute similarity between the radiological appearances of pneumonias and of atelectasis produced experimentally in dogs, including the mediastinal displacement. In humans as well, Jaches (1928) found that massive atelectasis produces practically the same density of a lobe or whole lung as lobar pneumonia. This was confirmed by Griffith (1927), as well as by the radiographs of the present series.

The localization of the lesion mainly to the bases cannot be brought as evidence in favour of atelectasis. Beddard reports basal localization in $75 \%$ of all pneumonia cases, an incidence which corresponds to that found in post-operative lung lesions. Table VII reproduces the localization figures of Mastics and others (1927) for postoperative atelectasis, and Elwyn's (1922) for post-operative pneumonia. The similarity of the two sets of figures is striking.

TABLE VII

Localization of Post-operative Atelectasis and PNEUMONIA

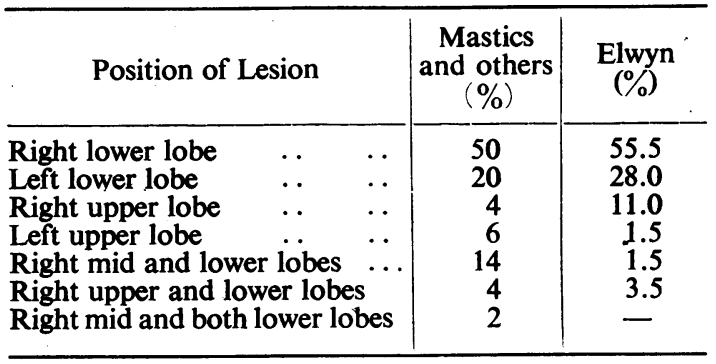

Even the mediastinal displacement to the side of the lesion so often quoted as evidence of atelectasis occurs, in the experimental animal as well as in man, both in atelectasis and in inflammatory lesions of the lung. Thoenes (1922) reported 11 cases of lobar pneumonia with displacement of the mediastinum. Engel (1926) pointed out that elevation of the diaphragm on the side affected was common in lobar pneumonia. Griffith (1927) concluded that lobar pneumonia at times produced similar radiological pictures to massive atelectasis, and Coryllos and Birnbaum (1928) confirmed these observations by reference to their own material. Even if displacement of the mediastinum signifies some degree of atelectasis, only a minority of the patients with post-operative lung lesions of doubtful aetiology show this displacement. Boland and Sheret (1928) found only one in every six patients with cardiac displacement, and in the present series only 24 out of 64 cases belonging to this group showed any displacement of the heart or diaphragm towards the lesion.

It is, therefore, obvious that the character of the radiological shadow, its localization, and the position of the heart and diaphragm in relation to it are similar in atelectasis and in inflammatory lung lesions. The radiological appearances cannot, therefore, be quoted in support of either factor as the cause of these lesions.

Clinical Evidence.- The clinical evidence in support of atelectasis is also poor. The sudden onset of symptoms and pyrexia occurs in many respiratory infections, such as lobar pneumonia, as well 
as in the group labelled here as bronchitis, where no atelectasis can be incriminated as the cause of the symptoms. In the latter, the temperature does not rise more than one or two degrees unless complicated by secondary infection, when, low at first, it gradually rises as infection supervenes. This course of events is not found in the group under discussion, where pyrexia of $101-103^{\circ} \mathrm{F}$. is registered within 24 to 48 hours after operation. The tenacious sputum also occurs in many lung infections. On the other hand, its early purulent character suggests an infection as the primary cause. This contention is strengthened by the gradual subsidence of the temperature and symptoms in 63 of the 64 patients observed, as well as the slow resolution of the radiological opacities.

A comparison between post-operative bronchitis and post-operative lung lesions will show the extreme similarity of the clinical picture. The sudden onset of temperature accompanied by cough and purulent sputum, subsiding gradually over a period of seven to 14 days, is common to both post-operative complications (King, 1933). The single outstanding difference between them is the presence of a lung lesion in one and its absence in the other. As it is absent in bronchitis, atelectasis cannot be the cause of the clinical picture, which must be due to an infection. As the symptoms, temperature chart, and sputum are the same in the post-operative complications with radiological evidence of lung lesions it is reasonable to assume that here too infection is the primary cause.

Bronchoscopic Evidence.-Bronchoscopic evidence in support of atelectasis as the primary cause of these complications is not convincing. Many bronchoscopic examinations have been performed on patients in whom infection of the trachea and bronchi was present, but no intrabronchial agent was found which could possibly produce bronchial obstruction and atelectasis (Brunn and Brill, 1930; Nosworthy, 1944). Sputum is the only possible agent that might block a bronchus in these cases. Its absence in those showing radiological shadows throws doubt on the theory of atelectasis being their cause. At the same time the constant presence of inflammatory signs in the trachea and bronchi, however early the examination is carried out, implies an infection of these structures.

In other cases bronchoscopic examination reveals the presence of purulent sputum in some and tenacious exudate in others. The exudate is necessarily a result of the infection of the air passages. This is, in fact, invariably present. In most cases reported the removal of this exudate produced only slight clinical and radiological improvement, but even that slight degree of recovery was not permanent, the patient relapsing within a short period of aspiration (Jackson and Lee, 1925 ; Tucker, 1926 ; Hearn and Clerf, 1927 ; Lee, Clerf, and Tucker, 1928 ; Brunn and Brill, 1930 ; Holinger, 1938).

It is clear from this evidence that obstruction to the bronchi is only rarely found on bronchioscopic examination of patients with the respiratory complications under discussion. On the other hand, signs of infection of the respiratory mucous membrane, with or without purulent exudate, are invariably present. There is no doubt that in some cases the tenacious sputum may produce an obstruction of a bronchus and collapse of the lung beyond it, whether normal or already infected. The collapse, however, is a secondary complicating process following the primary infection. Bronchoscopic aspiration of exudate which might be blocking a bronchus deals with the secondary factor but does not influence the course of the primary infection. The partial relief and its temporary nature are thus explained.

Pathological Evidence.-Direct evidence from pathological material is scarce, partly because of the innocent character of this type of respiratory complication, and partly because it as a rule resolves within a few days of operation, a period usually survived by patients destined to die later on. A few post-mortem reports bearing on this problem have appeared from time to time.

Whipple in 1918 reported a necropsy on a patient dying 36 hours after operation, in whom physical signs in the chest were discovered ten hours before death. The lungs showed no definite consolidation, but very marked congestion, accompanied by fibrin-free exudate into the alveoli. Radiographs of the lungs at necropsy showed the same shadows as those in the radiographs taken a few hours before death. He believed that an infection with pneumococcal organisms of low virulence would produce similar lesions in the lungs. In support of his view he quotes the experimental work of Wollstein and Meltzer (1913), who produced corresponding lung lesions in dogs whose bronchi were insufflated with pneumococe of low virulence. Whipple reports seven other necropsies on patients who suffered from postoperative respiratory complications. As these necropsies were carried out many days after operation, the relation of the lung pathology to the respiratory symptoms is doubtful. 
Jackson and Lee (1925) reported two necropsies, one on a negress 18 years old who died three days after caesarean section. The right lower lobe was purple in colour, with many dark patches. A close inspection revealed groups of air-containing pulmonary lobules. The left lower lobe was dark and contained no air, but compression of pulmonary tissue caused the expression of thick pus from the bronchi. Dissection of the bronchial tree revealed tenacious muco-pus filling the bronchi to the left lower lobe. On section, all bronchioles contained exudate rich in fibrin, in the meshes of which closely packed polymorphs were seen. Around the lumen of infected bronchioles there were tightly packed alveoli showing signs of broncho-pneumonia. The second necropsy was on a case operated on under local anaesthetic for a strangulated hernia. The upper lobe was the seat of lobar pneumonia. Below the hilum an abscess about $3 \mathrm{~cm}$. in diameter was found. This abscess was in direct communication with the bronchus to the lower lobe, which was occluded and the lung beyond it partially collapsed. In addition to the collapse there were small areas of consolidation.

Boland and Sheret (1928) reported one necropsy of a patient who died seven days after the onset of a post-operative pulmonary complication diagnosed as atelectasis. The right lower lobe was shrunken, firm, and airless. All bronchi were filled with pus. Microscopically it was impossible to differentiate the lesion from an ordinary broncho-pneumonia. They further stated that a true uncomplicated 'case of pure collapse has never come to necropsy. The smaller bronchi are filled with fibro-purulent plugs around which are areas indistinguishable from broncho-pneumonia.

Brock in 1936 reported four necropsies in patients who developed respiratory complications and died within a few days of the operation. Of these, three showed broncho-pneumonic areas only in the lobe that was diagnosed to be atelectatic. The fourth patient was a child aged 6, on whom capsulotomy of the shoulder joint was performed. Twenty-four hours after operation his temperature rose and his general condition deteriorated rapidly. Bilateral atelectasis was diagnosed and confirmed at necropsy. No further dețails are given of this necropsy, but as no obstruction was found in the bronchi one has to assume the atelectasis to be neurogenic in origin due to interference with the mechanism of respiration. This type of atelectasis has been produced experimentally and described as accompanying certain traumatic chest injuries and operations. It is, however, extremely rare, and can be discarded in discuss- ing the aetiology of the common post-operative respiratory complications.

In the present series only one patient with a respiratory complication died within three days after operation. The right lower lobe showed red $\cong$ hepatization which was definitely pneumonic and $\nRightarrow$ not atelectatic. Four other necropsies were $\vec{\circ}$ carried out on patients who suffered from respiratory complications. Two showed congestion and oedema, and two had multiple bilateral bronchopneumonic areas in the middle and lower zones of both lungs. One of these patients showed an area of suppuration about 1 in. in diameter in $N$ the right lower lobe. As these necropsies were $\vec{\circ}$ carried out many days after operation, the relation between the pathological findings and the original respiratory complication is doubtful.

It is obvious from this review of the pathological findings that infection of the bronchial tree is always present at necropsy, whereas atelectasis, although common, is not invariable. When present it is due to bronchial obstruction caused by exudate secreted as a result of the inflammation of the respiratory passages.

The common presence of infection and atelectasis in those complications and the evidence from the experimental production of pneumonia and atelectasis in animals led Coryllos and Birnbaum (1928) to suggest that in both lobar pneumonia and post-operative lung lesions atelectasis occurs first, to be followed by infection in that part of the lung. This explanation, although accounting for many of the facts discussed above, will not account for the clinical similarity between those with and without lung involvement. The occurrence of post-operative bronchitis cannot depend on preceding atelectasis, as no lung changes are found in this group. It must depend on infection by one or more organisms. If atelectasis is, therefore, not a prerequisite of bronchial infection, why should it be so in those cases with lung involvement ? N

The conception of infection as the main precipitating factor in the pathogenesis of postoperative complications with lung shadows brings Group D into line with the rest of this series, excluding the vascular lesions (Group A, Table I). In all these groups infection plays the primary part in determining the clinical picture, prognosis, and treatment. It is derived most commonly from the respiratory tract, and rarely from the site of operation. It is conveyed to the lower respiratory tract by the bronchi and rarely by the blood stream. It is retained there because of the inhibition of expiratory forces by pain from traumatized abdominal muscles. With the reduction of the 
general and local resistance of the patient invasion of the tissues takes place.

The causative organism initiating the respiratory inflammatory process remains unknown. Whipple (1918) found pneumococci belonging to Group 4 in the sputa of the majority of his patients who suffered respiratory complications. Serum collected from seven of these patients up to the third post-operative day did not agglutinate the pneumococci which were found in their sputum. If, however, the serum was taken later on in the disease, agglutination was found to take place in many of these cases. In the present series, pneumococci were found in a small number of patients, whereas two-thirds of the patients showed Strep. viridans alone or in combination with other organisms. Whether pneumococci of low virulence or Strep. viridans or both are the organisms responsible for these obscure respiratory infections cannot be answered with the material and knowledge at present available. The relation of these complications to epidemic pneumonitis of questionable virus origin is another problem awaiting solution.

\section{SYMPTOMATOLOGY}

The symptomatology of post-operative respiratory complication depends partly on the mechanical interference with the function of respiration as occurs in embolus, pulmonary oedema, and atelectasis, and partly on infection of the bronchi, lung, and pleura. In the majority of cases the two factors play a combined role: infection may be complicated by atelectasis, and emboli may become secondarily infected. It is therefore essential to keep in mind both the primary and secondary factors in the estimation of prognosis and in the planning of treatment.

\section{Prognosis}

Of the total number of patients (810) 59 have died $(7 \%)$. The number of deaths in those who suffered no post-operative respiratory complication (666) was $30(4.5 \%)$, while in those who suffered these complications it was $29(20 \%)$. Of the deaths in the latter group 13 were directly due to the respiratory complications, six followed pulmonary emboli, two pulmonary oedema, three staphylococcal infection, one Friedländer's bacillus infection, and one an empyema. The deaths caused by respiratory complications thus accounted for $1.6 \%$ of the total number of patients operated on, for $9 \%$ of the patients who developed respiratory complications, and for $22 \%$ of the total number of deaths.
If those who died from respiratory complications are excluded, we are still left with 16 deaths in 131 patients (12\%) who developed respiratory complications but in whom the latter were not the cause of death. This high death incidence of $12 \%$ compared with $4.5 \%$ in those who suffered no respiratory complication can be explained by the fact that patients in poor general health, and therefore poor surgical risks, manifested a higher incidence of respiratory complications. Their general health was further undermined by these complications, thus reducing their chances of survival.

The prognosis, therefore, is affected adversely in any patient who develops a respiratory complication in the post-operative period. In some, such as those with staphylococcal lung infections; suppurative pneumonia, and lung abscesses, it is grave, the respiratory complication being the main cause of death. In others, such as cases of bronchitis, pneumonitis (with or without atelectasis), it is poorer than in those who do not develop these complications, because of their higher incidence in debilitated persons and their continuous drain on the vital reserves of the patient.

\section{TREATMENT}

The prevention of post-operative respiratory complication is difficult in view of the peculiar nature of the aetiological factors concerned. The poor general condition of the patient, if not dependent on the disease which necessitates operation, can perhaps be improved before operation by diet, transfusion, and other means. No operation should be undertaken on patients suffering from an acute respiratory infection. Those with chronic respiratory infections should, if possible, be operated on in the warmer months of the year, the operation being preceded by postural drainage, breathing exercises, and if indicated, by chemotherapy.

Following operation patients should be encouraged to breathe normally and use the abdominal muscles both in inspiration and expiration, normal and forced. Ward breathing exercises under the direction of a trained physiotherapist have been tried for a few months in this series, with inconclusive results.

In the treatment of the established disease, the infection of the respiratory tract, as well as the mechanical factors which tend to diminish the oxygenating surface of the lung, need attention. The infection can be treated by chemotherapy, and the reduction in the oxygenating lung surface by oxygen inhalation. Mucus and pus obstructing 
the bronchi and causing some atelectasis can be dealt with by postural drainage, inhalations of carbon dioxide with oxygen, and menthol inhalations. The uniformly good results achieved in the respiratory complications of doubtful origin without the use of bronchoscopic aspirations throw doubt on the value of this procedure.

\section{SUMMARY}

A clinical study was made of post-operative respiratory complications in 810 patients who had undergone 1,000 genito-urinary operations.

One hundred and forty-four patients, $18 \%$ of the number operated on, developed 160 respiratory complications, amounting to $16 \%$ of the total number of operations carried out.

The pre-operative condition of the patients who developed respiratory complications is compared with those in whom recovery was uneventful. It was found that the sex, age, general health, and the condition of the respiratory passages were all factors of importance in determining the incidence of respiratory complications in the post-operative period

The importance of trauma to abdominal muscles in inhibiting expiratory efforts and thus allowing the retention of infective material is once more emphasized.

It is suggested that the primary factor in all postoperative respiratory complications, excluding the vascular group, is infection. The inflammatory exudate, however, may cause bronchial obstruction and, secondarily, atelectasis.

The prognosis and treatment of these lesions depend mainly on the nature and extent of the infection to bronchi, lung, and pleura. Atelectasis, when present in post-operative respiratory complications, plays only a small part in the evaluation of the prognosis and the planning of the treatment.

My thanks are due to Mr. F. J. F. Barrington, Mr. H. Winsbury-White, Mr. R. Ogier Ward, Mr. J. Parton, and Mr. J. A. Currie for permission to investigate the patients under their care, and to Mr. G. Qvist, who carried out the thoracic surgery.

\section{REFERENCES}

Andrus, W. D. (1925). Arch. Surg., Chicago, 10, 506. Armstrong, G. E. (1906). Brit. med. J., 1, 1141 . Beddard, A. P., in Pembrey, M. S., and Ritchie, J., Texthook of General Pathology, London, 1913.

Boland, C. R., and Sheret, J. E. (1928). Lancet, 2, 111.
Brock, R. C. (1936). Guy's Hosp. Rep., 86, 191.

Brunn, H., and Brill, S. (1930): Ann. Surg., 92, 801.

Churchill, E. D. (1925). Arch. Surg., Chicago, 11, 489.

Churchill, E. D. (1925). Arch. Surg., Chicago, 11, 489.

Coryllos, P. N., and Birnbaum, G. L. (1928). Arch. Surg., Chicago, 16, 501.

Cutler, E. C., and Hunt, A. M. (1920). Arch. Surg., Chicago, 1, 114.

Cutler, E. C., and Morton, J. J. (1917). Surg. Gynec. Obstet., 25, 621.

Eliason, E. L., and McLaughlin, C. (1932). Surg. Gynec. Obstet., 55, 716.

Elliot, T. R., and Dingley, L. A. (1914). Lancet, 1, 1305.

Elwyn, H. (1922). J. Amer. med. Ass., 79, 2154.

Engel, S. (1926), in Pfaundler, M., and Schlossmann, A., Handbuch Kinderheilkunde, Leipzig, 3, 636.

Foss, H. L., and Kupp, J. H. (1930). Surg. Gynec. Obstet., 51, 798.

Gray, H. K. (1933). Proc. Mayo Clin., 8, 70.

Griffith, J. P. C. (1927). Amer. J. med. Sci., 174, 448.

Harris, T. A. B. (1942). Brit. J. Anaesth., 18, 11.

Hearn, W. P., and Clerf, L. H. (1927). Ann. Surg., Chicago, 85, 54.

Holinger, P. H. (1938). Surg. Clin. North Amer., 18, 237.

Holmes, G. W. (1924). Amer. J. Roentgenol., 11, 509.

Jaches, L. (1928). J. Amer. med. Ass., 90, 612.

Jackson, C., and Lee, W. E. (1925). Ann. Surg., Chicago, $82,364$.

King, D. S. (1933). Surg. Gynec. Obstet., 56, 43.

Lee, W. E., Clerf, L. H., and Tucker, G. (1928). Ann. Surg., Chicago, 88, 6.

Lee, W. E., Ravdin, J. S., Tucker, G., and Pendergrass, E. P. (1923). Ann. Surg., Chicago, 88, 15.

Lichtheim, L. (1878). Arch. exp. Path. Pharmak., 10, 54.

Lucas, B. G. B. (1943). Proc. R. Soc. Med., 37, 145.

MacCallum, W. G. (1908). Johns Hopk. Hosp. Bull., 19, 215.

Mann, K. J. (1946). Lancet, 2, 744.

Mastics, E. A., Spittler, F. A., and McNamee, E. P. (1927). Arch. Surg., Chicago, 15, 155.

Mathes, M. E., and Holman, E. (1929). Cal. West Med., 31, 386.

Mendelssohn, A. (1845). Der Mechanismus der Respiration und Cirkulation, B. Behrs, Berlin.

Nosworthy, M. D. (1944). Proc. R. Soc. Med., 37, 303.

Oswald, N. C. (1938). Proc. R. Soc. Med., 31, 1272.

Pasteur, W. (1914). Brit. J. Surg., 1, 587.

Rabdin (1938).

Rovenstine, E. A., and Taylor, I. B. (1936). Amer.'J. med. Sci., $191,807$.

Scrimger, F. A. C. (1922). Amer. J. Surg. Q. Supp. Anaes., N.Y., 36, 50.

Scott, W. J. M. (1925). Arch. Surg., Chicago, 10; 73.

Stewart, C. C. (1932). Canad. med. Ass. J., 26, 55.

Thoenes, F. (1922). Mschr. Kinderheilk., 23, 353.

Traube, (1846).

Tucker, G. (1926). Surg. Gynec. Obstet., 42, 743.

Whipple, A. O. (1918). Surg. Gynec. Obstet., 26, 29.

Wollstein, M., and Meltzer, S. J. (1913). J. exp. Med. $17,353$. 